\title{
Iodane-Guided C-H Cleavage to Synthesize Densely Functionalized Arenes
}

\author{
Aleksandra Nilova, ${ }^{a}$ Paul A. Sibbald,${ }^{b}$ Edward Valente, ${ }^{c}$ Gisela A. González-Montiel, ${ }^{d}$ H. Camille Rich- \\ ardson, ${ }^{d}$ Kevin S. Brown, ${ }^{e}$ Paul Ha-Yeon Cheong, ${ }^{* d}$ and David R. Stuart*a \\ ${ }^{a}$ Department of Chemistry, Portland State University, Portland, Oregon 97201, United States \\ ${ }^{b}$ Department of Chemistry, Stetson University, DeLand, Florida 32723, United States \\ ${ }^{c}$ Department of Chemistry, University of Portland, Portland, Oregon 97203, United States \\ ${ }^{d}$ Department of Chemistry, Oregon State University, Corvallis, Oregon 97331, United States \\ ${ }^{e}$ Department of Pharmaceutical Sciences and Chemical, Biological, and Environmental Engineering, Oregon State Univer- \\ sity, Corvallis, Oregon 97331, United States
}

\section{Supporting Information Placeholder}

\begin{abstract}
Herein, we describe a strategy for the iodaneguided functionalization of sterically congested $\mathrm{C}-\mathrm{H}$ bonds, which is distinct from electronic, steric or proximity guided $\mathrm{C}-\mathrm{H}$ functionalization methods. Readily accessible aryl(Mes)iodonium salts serve as the starting materials or intermediates in these reactions and produce complex 1,2,3,4-substituted arenes via aryne intermediates. This approach is especially powerful when coupled with the innate $\mathrm{C}-\mathrm{H}$ functionalization reactivity of simple arenes, to replace two $\mathrm{C}-\mathrm{H}$ bonds with two $\mathrm{C}-\mathrm{C}$ or $\mathrm{C}$-heteroatom bonds while overriding steric effects that typically inhibit such reactions. DFT studies reveal a contribution of inductive, resonance, and steric effects on the regioselectivity of $\mathrm{C}-\mathrm{H}$ cleavage and aryne generatation.
\end{abstract}

Densely functionalized arenes with a contiguous arrangement of substituents are found in drugs, agrochemicals, and functional materials. Within this class, 1,2,3,4-substituted benzenoid rings are a component of the active pharmaceutical ingredients Naloxone and Cobimetinib, and the pesticide Tembotrione, among many others (Scheme 1a). Contiguous ring substituents, even two, have a dramatic influence on both structure and reactivity due to steric strain ${ }^{1}$ and a so called "buttressing" effect. ${ }^{2}$ However, despite both theoretical and applied interest in contiguously substituted arenes there are few general methods to access more highly substituted members of this family. Synthetic strategies to prepare functionalized benzenoid rings are highly sensitive to steric effects and therefore rendered ineffective to install contiguous substituents. For instance, many well-established $\mathrm{C}-\mathrm{H}$ functionalization reactions that proceed by broadly distinct mechanisms functionalize the most sterically accessible position (Scheme $1 \mathrm{~b}$ ). ${ }^{3}$ Additionally, construction of the arene core from unsaturated precursors typically places non-tethered substituents distal to other substituents (Scheme 1b). ${ }^{4}$ Collectively, these strategies produce contiguously substituted arenes as the minor product, if at all. The development of reactions that overcome inherent substrate steric effects and functionalize hindered positions has not kept pace with these other aforementioned reactions. The consequence of this disparity is that contiguously substituted patterns are difficult to access, and densely func- tionalized building blocks are rare. Moreover, new synthetic methods that regioselectively functionalized sterically hindered positions have the potential to expand arene chemical space.

$\mathrm{C}-\mathrm{H}$ functionalization remains an attractive strategy to functionalization arenes cores due to its intrinsic efficiency. Kinetic depro-

Scheme 1. Approach to densely functionalized arenes.
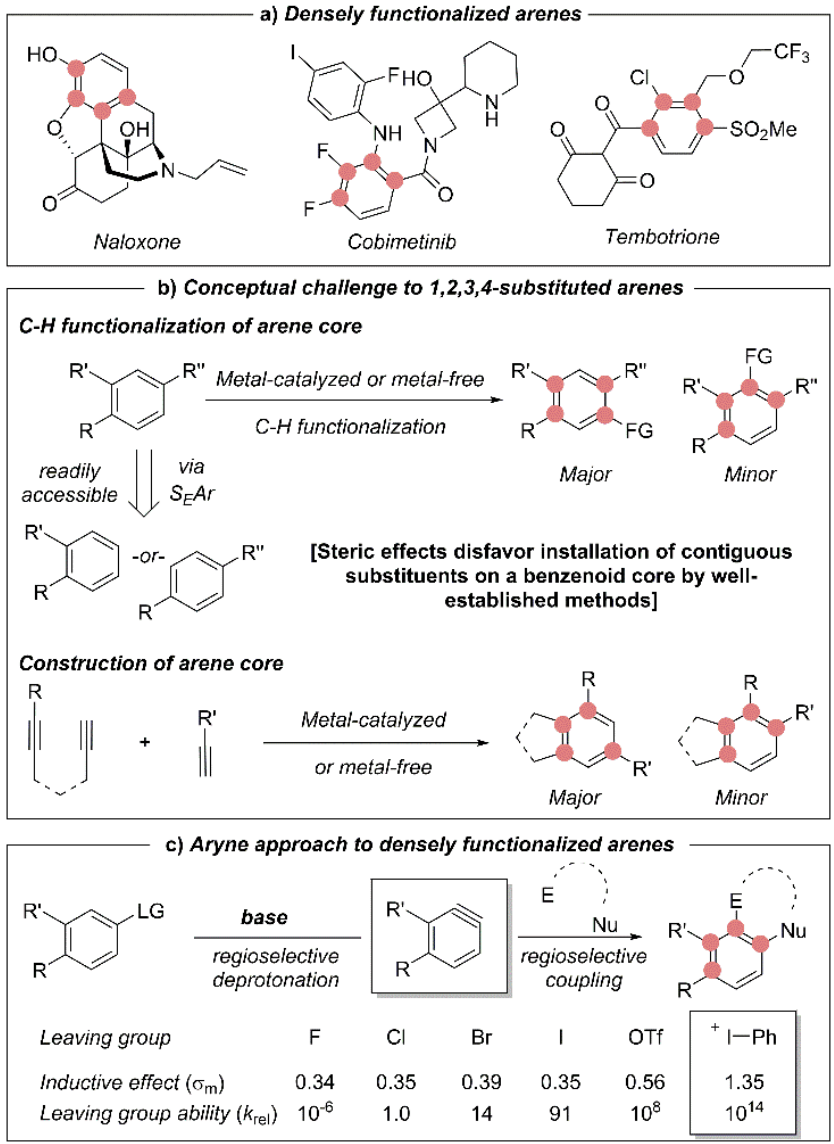
tonation/trapping of acidic arene $\mathrm{C}-\mathrm{H}$ bonds is uniquely suited to override inherent steric effects. However, equilibration between kinetic and thermodynamic anions is substrate dependent and therefore limits the generality of this approach. ${ }^{5}$ Moreover, the unintended departure of labile ortho-leaving groups leads to arynes reducing the yield of the intended product. Yet, arynes are enticing intermediates to access densely functionalized arenes if they can be strategically used as an element of reaction design (Scheme 1c). For example, can regioselective $\mathrm{C}-\mathrm{H}$ deprotonation be coupled with regioselective ${ }^{6}$ addition of two new substituents across the transient aryne to access 1,2,3,4-substituted arenes from readily available arene starting materials ? ${ }^{7}$ With this goal in mind, mono-functional aryne precursors are paramount (Scheme 1c). ${ }^{8}$ A resurgence in this approach has focused on (pseudo)halide leaving groups, ${ }^{9}$ but aryl carboxylic acids ${ }^{10}$ and arylboronic acids ${ }^{11}$ have also been used as substrates. Despite the attractive simplicity of mono-functional aryne precursors, three key complications exist. (1) Side reactions are well documented, including thia-Fries rearrangements of orthometallated aryl triflates, ${ }^{12}$ competitive leaving group departure from polyhalo arenes, ${ }^{9 f, 13}$ and competitive nucleophilicity of the base. ${ }^{9 f, g, 13,14}$ (2) In some reactions the regioselectivity of C-H deprotonation remains low or occurs at the most sterically accessible proton, making these methods unsuitable for synthesis of densely functionalized arenes. ${ }^{9 \mathrm{~d}, \mathrm{e}, \mathrm{g}, \mathrm{h}, 11}$ (3) Many reactions require strong, air-sensitive amide bases, ${ }^{9 b, d, e, g, h}$ cryogenic temperatures, ${ }^{9 e}$ or weaker alkoxide bases at high temperatures $\left(>120{ }^{\circ} \mathrm{C}\right),{ }^{9 a, c, d}$ thus introducing practical limitations. Herein, we describe an approach that draws on the strong inductive withdrawing effect and hypernucleofugality of aryliodonium leaving groups (as estimated by $\sigma_{m}$, Scheme $1 \mathrm{c})^{15}$ to address the aforementioned complications of mono-functional aryne precursors. Our approach allows for room temperature $\mathrm{C}-\mathrm{H}$ deprotonation in a highly regioselective manner with chemoselective ejection of the iodonium leaving group, leading to densely functionalized 1,2,3,4-substituted arenes after aryne capture. Mechanistic investigation by DFT provides a nuanced understanding of the regiocontrol over $\mathrm{C}-\mathrm{H}$ deprotonation.

Table 1. Influence of reaction conditions. ${ }^{a}$

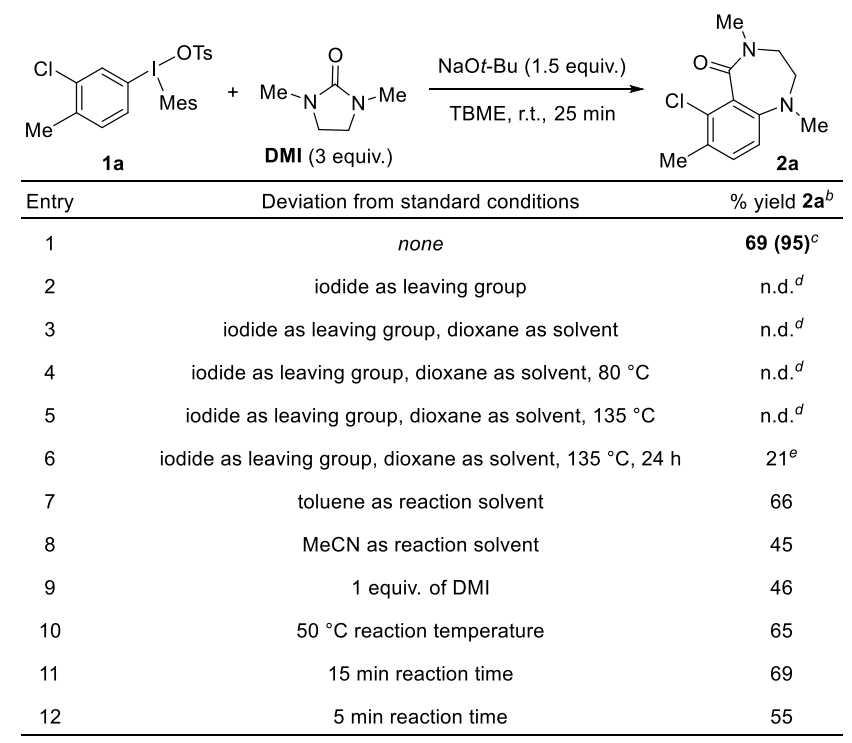

${ }^{a}$ Conditions: 1a ( $0.1 \mathrm{mmol}, 1$ equiv.), DMI ( $0.3 \mathrm{mmol}, 3$ equiv.), $\mathrm{NaO} t$-Bu (0.15 mmol, 1.5 equiv.), TBME (0.5 mL), r.t., $25 \mathrm{~min}$. ${ }^{b}$ Determined by ${ }^{1} \mathrm{H}$ NMR spectroscopy with 1,3,5-trimethoxybenzene as internal standard. ${ }^{c} 95 \%$ consumption of $1 \mathrm{a}$ based on integration of iodomesitylene by-product. ${ }^{d}$ n.d. $=$ not detected. ${ }^{e}$ Average of two runs (16 and $25 \%$ yield) using conditions from ref. $10 \mathrm{e}$
As an entry point to this strategy, we selected compound 1a as aryne precursor ${ }^{16}$ and dimethyl imidazolidone (DMI) as arynophile, which leads to medicinally relevant aryl diazepinone $\mathbf{2 a}$ via $\sigma$-bond insertion of an aryne into a urea $\mathrm{C}-\mathrm{N}$ bond. Although aryl diazepinones are desirable targets for medicinal chemistry, only two examples that contain a 1,2,3,4-substituted benzenoid core have been described in the literature. ${ }^{17}$ Under our previously reported conditions ${ }^{18}$ to generate arynes, with aryl(Mes)iodonium salts and LiHMDS in toluene, we obtained a modest yield of $\sim 20 \%$. An extensive survey of bases, solvents, temperature, and reagent stoichiometry provided conditions that vastly improved the yield of 2a. Employing 1.5 equiv. of $\mathrm{NaO} t$-Bu as base in $\mathrm{TBME}$ as solvent, we achieved room temperature regioselective $\mathrm{C}-\mathrm{H}$ deprotonation and trapping of the aryne with 3 equiv. of DMI (Table 1, entry 1; $69 \%$ yield). We also assayed the consumption of 1 a at $95 \%$ based on the observation of the mesityl iodide by-product (Table 1, entry1). The monovalent iodide leaving group did not lead to any observable quantity of $\mathbf{2 a}$ (Table 1 , entry 2 ), and other solvents (1,4-dioxane) and higher temperatures $\left(80\right.$ and $\left.135^{\circ} \mathrm{C}\right)$ did not produce 2a (Table 1, entry 3-5). When the iodide leaving group was employed in 1,4-dioxane at $135^{\circ} \mathrm{C}$ for 24 hours we did observe variable but low quantities of $\mathbf{2 a}$ (Table 1 , entry 6 ). The contrast in conditions required for iodide $v$ iodonium leaving groups is striking: $135{ }^{\circ} \mathrm{C}$ for 24 hours ( $21 \%$ yield) vs room temperature for 25 minutes (69\% yield), and is consistent with the dramatically greater inductive effect of iodonium relative to other (pseudo)halides

\section{Chart 1. Scope of aryl(Mes)iodonium tosylate salts. ${ }^{a}$}

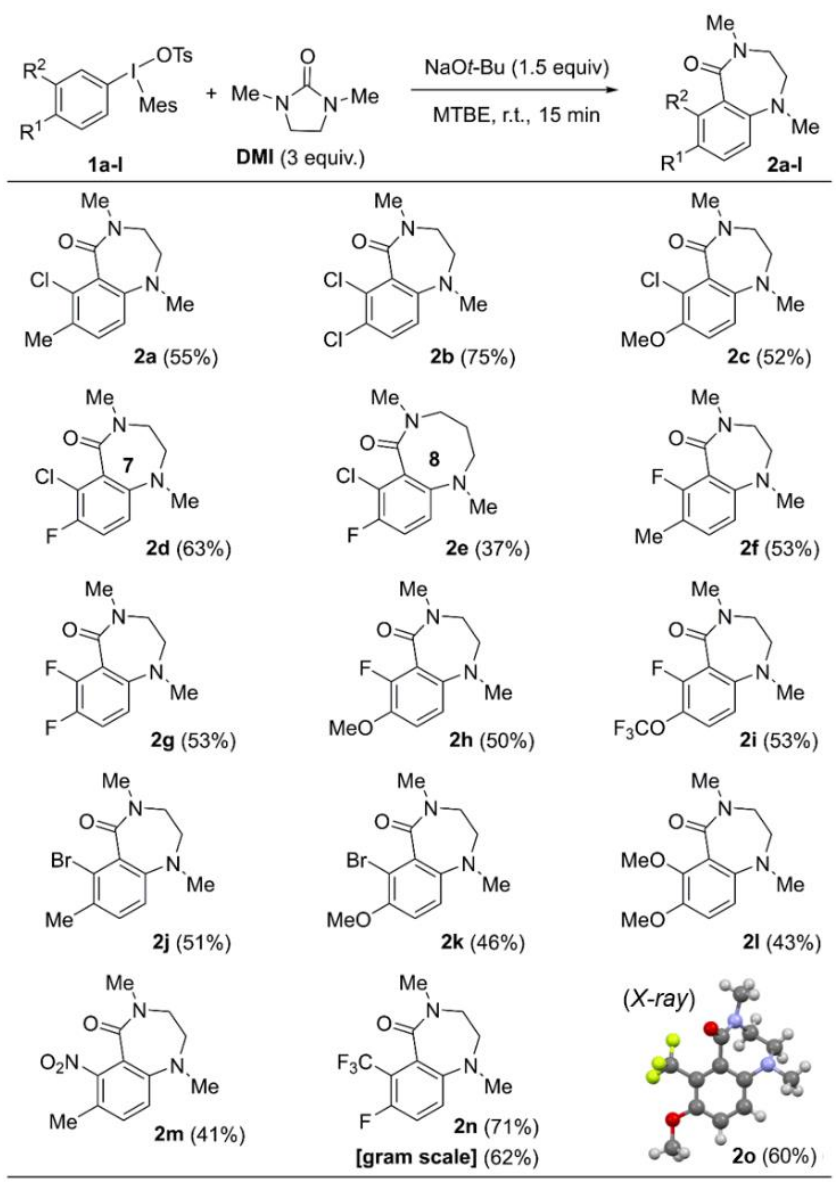

${ }^{a}$ Conditions: 1 ( 0.5 mmol, 1 equiv.), DMI (1.5 mmol, $1-3$ equiv.), $\mathrm{NaO} t$-Bu (0.75 mmol, $1.5-3$ equiv.), MTBE (2.5 mL), r.t., $15-40$ min; see SI for variations. 
(Scheme 1e). Other relevant aspects of the reaction conditions are presented in Table 1: toluene provides similar yield of product, though acetonitrile resulted in lower yield of 2a (Table 1, entry 7 and 8). Decreasing the equivalents of urea, resulted in lower yield of 2a (Table 1, entry 9), and increasing the reaction temperature had a negligible impact on the yield of $\mathbf{2 a}$ (Table 1, entry 10). ${ }^{19}$ Finally, we found that similar yield of $\mathbf{2 a}$ was observed after 15 minutes of reaction time and a moderate yield of $55 \%$ was observed after only 5 minutes of reaction time (Table 1, entry 11 and 12).

Chart 1 contains examples of selected aryl(Mes)iodonium salts that are compatible under our standard conditions. The isolated yields range from $43-75 \%$, and high regioselectivity was observed for both $\mathrm{C}-\mathrm{H}$ deprotonation and addition of the $\mathrm{C}$ and $\mathrm{N}$ atoms of urea across aryne intermediate. ${ }^{20}$ Relevant to the regioselectivity of C-H deprotonation, several groups are compatible meta- to the iodonium leaving group $\left(\mathrm{Cl}\right.$ : $\mathbf{2 a - e}, \mathrm{F}: \mathbf{2 f - i}, \mathrm{Br}: \mathbf{2 j}, \mathbf{k}, \mathrm{OMe}$ : $\mathbf{2 l}, \mathrm{NO}_{2}$ : $2 \mathbf{m}$, and $\mathrm{CF}_{3}: \mathbf{2 n}, \mathbf{o} ;$ Chart 1$)$. Fluoride and fluorinated groups $\left(\mathrm{CF}_{3}\right.$, 2n, $\left.2 \mathbf{o} ; \mathrm{OCF}_{3}, \mathbf{2 i}\right)$ are prevalent in medicinal chemistry and these products represent new building blocks incorporating fluorine. Additionally, the inclusion of chloride (2a-e) and bromide $(\mathbf{2} \mathbf{j}, \mathbf{k})$ allows for further elaboration of these densely functionalized building blocks by transition metal catalysis. Finally, the X-ray structure of 20 illustrates the extreme steric congestion present in these products. Closer inspection reveals an out of plane dihedral angle for the benzenoid ring carbons of $6.06^{\circ}$, which is consistent with dihedral angles observed in highly congested hexasubstituted benzenoid rings. $^{21}$

As highlighted above, the incorporation of chloride and bromide groups in the aryl diazepinone products provides an opportunity for further functionalization of the benzenoid core. The bromide leaving group in $\mathbf{2} \mathbf{j}$ is substituted for an aryl group, an amine, or an alkenyl group via Suzuki, Buchwald-Hartwig, and Heck coupling reactions respectively. ${ }^{22}$ Each coupling product is obtained in high yield (3a-c, Scheme 2), and the X-ray structure of $\mathbf{3 c}$ shows the Econfiguration of the alkene product.

Scheme 2. Derivatization of aryl diazepinone $2 \mathrm{~b}^{a}{ }^{a}$

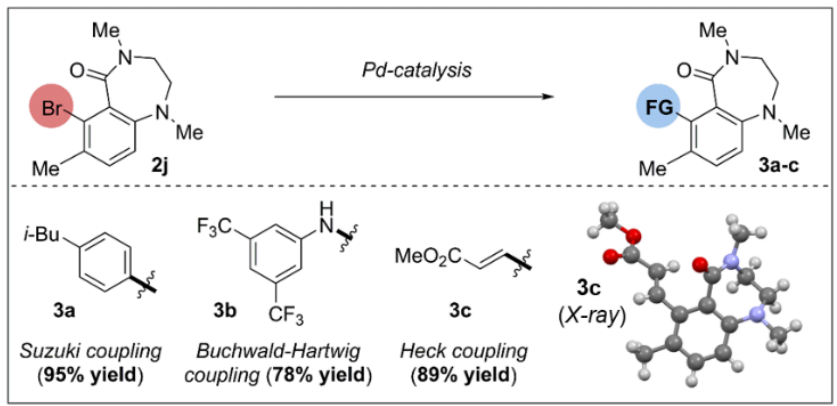

${ }^{a}$ See SI for detailed conditions.

We have also demonstrated that other arynophiles participate in this general strategy to access a range of 1,2,3,4-substituted benzenoid cores (Chart 2). Cycloaddition with 2-(trimethylsiloxy)furan or $N$-tert-butylphenylnitrone yielded annulated products $\mathbf{4 a}$ and $\mathbf{4 b}$, respectively. Reaction with pyridine $N$-oxide led to the heterobiaryl linkage in $\mathbf{4 c}$ with 1,2,3,4-substitution on the benzenoid ring. Regioselective insertion of the aryne intermediate into $\mathrm{N}-\mathrm{Cl}$ and $\mathrm{N}$ Si $\sigma$-bonds yielded $\mathbf{4 d - f}$. Although in some cases moderate yields were obtained, few other methods of arene $\mathrm{C}-\mathrm{H}$ functionalization are able to access the 1,2,3,4-substitution pattern with the efficiency obtained by this approach.

The full power of this strategy may be realized by coupling the innate regioselectivity of electron-rich arenes with the iodane guided regioselectivity for dual $\mathrm{C}-\mathrm{H}$ functionalization of readily available hydrocarbon feedstocks (Scheme 3a). We demonstrate
Chart 2. Representative arynophiles.

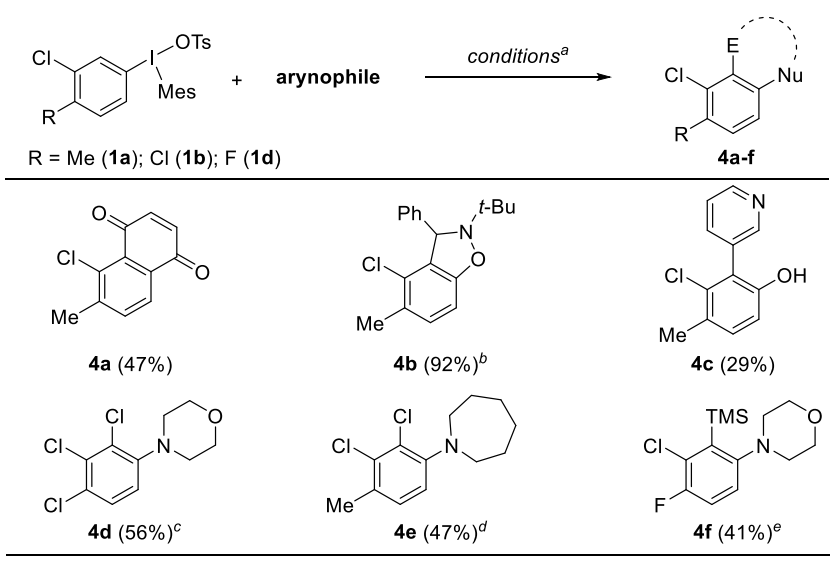

${ }^{a}$ Conditions: 1a ( $0.5 \mathrm{mmol}, 1$ equiv.), arynophile (1.1-3 equiv.), $\mathrm{NaO} t$-Bu (1.5-5 equiv.), MTBE (2.5 mL), r.t., 15-60 min.; see SI for variation. ${ }^{b}$ Isolated as a mixture of regioisomers (11:1), see SI. ${ }^{c}$ Used $\mathbf{1 b}$ as starting material. ${ }^{d}$ Isolated as a mixture of regioisomers (22:1), see SI. ${ }^{e}$ Used $\mathbf{1 h}$ as starting material.

this by sequential coupling reactions of 2-fluoroanisole (Scheme $3 \mathrm{~b}$ ). Diaryliodonium $\mathbf{1 h}$ is readily obtained in $74 \%$ yield by condensation of 2-fluoroanisole with [hydroxyl(tosyloxy)]iodomesitylene in acetonitrile at $50{ }^{\circ} \mathrm{C}$. The reaction occurs within three hours and the product is isolated by trituration. Treatment of $\mathbf{1 h}$ with $\mathrm{NaO} t$-Bu extrudes an aryne intermediate that undergoes annulation with several arynophiles to produce a range of nitrogen heterocycles (Scheme 3b). The total sequence to convert 2-fluoroanisole into $\mathbf{2 h}, \mathbf{5 a}$, or $\mathbf{5 b}$ by replacing two ortho aromatic $\mathrm{C}-\mathrm{H}$ bonds with $\mathrm{C}-\mathrm{C}, \mathrm{C}-\mathrm{N}$, and $\mathrm{C}-\mathrm{O}$ bonds requires $\sim 4$ hours and one chromatographic purification of the final heterocycle. Moreover, this approach to take a 1,2-substituted arene to a 1,2,3,4-substituted arene is virtually unparalleled in efficiency.

Scheme 3. Dual C-H functionalization reactions. ${ }^{a}$

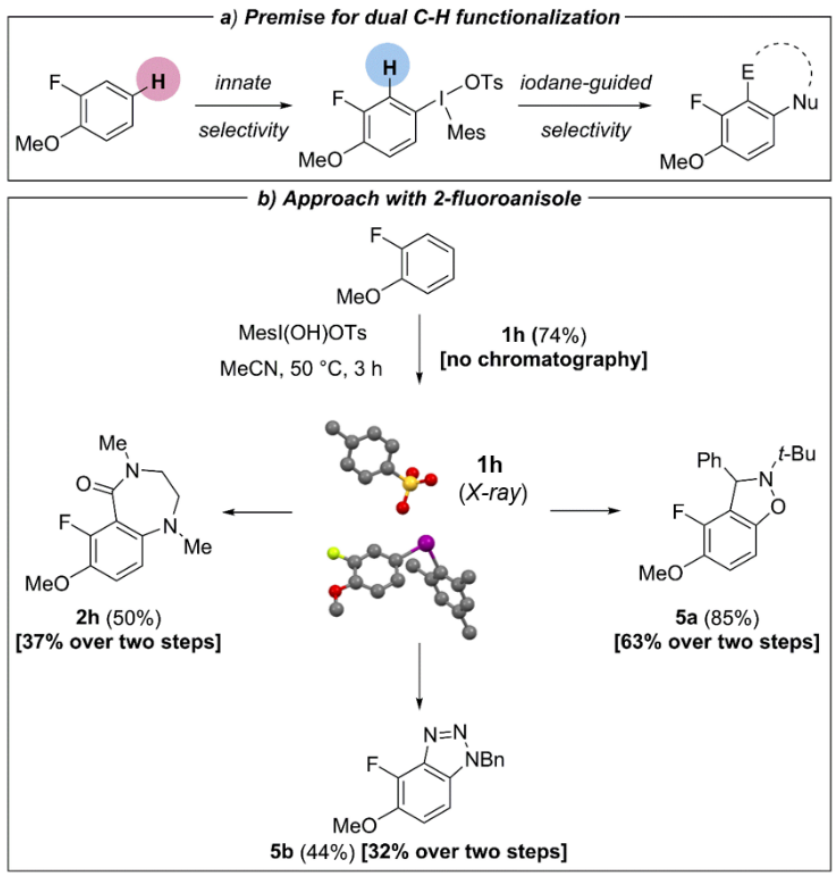

${ }^{a}$ Conditions: 1k: 2-fluoroanisole (1 mmol, 1 equiv.), MesI(OH)OTs ( $1 \mathrm{mmol}, 1$ equiv. $), \mathrm{TsOH} \cdot \mathrm{H}_{2} \mathrm{O}$ ( $1 \mathrm{mmol}, 1$ equiv. $)$, 
$\mathrm{MeCN}(1 \mathrm{~mL}), 50^{\circ} \mathrm{C}, 3$ hours. $2 \mathbf{k}, 5 \mathbf{a}, \mathbf{5 b}$ : $1 \mathbf{k}(0.5 \mathrm{mmol}, 1$ equiv. $)$, arynophile (1.1-3 equiv.), $\mathrm{NaO} t$-Bu (1.5-5 equiv.), MTBE (2.5 $\mathrm{mL})$, r.t., 15-60 min.; see SI for variation.

We have previously shown that the selectivity of C-H deprotonation ortho to iodonium leaving groups occurs in a contra-steric fashion, although the exact contribution of electronic and steric effects to regioselectivity was unclear. ${ }^{18 a}$ Here, we use DFT to provide further insight into the structural effects of the iodonium moiety and the transition states that dictate the observed selectivity. All major and minor aryne formation transition structures involving aryl(Mes)iodonium salts (1a-o) have been computed using the M06-2X density functional with the PCM solvation model for toluene. The LANL2DZDP basis set and effective core potential was used for iodine and 6-31G* was used for all other elements. ${ }^{23,24}$

Aryne formation occurs via a concerted process in which cleavage of the $\mathrm{C}-\mathrm{H}$ bond (2- or 6-position) and elimination of the iodo2,4,6-trimethylbenzene and sodium tosylate of the aryl(Mes)iodonium salt (1a-o) ${ }^{25}$ by $\mathrm{NaO} t \mathrm{Bu}$ are concurrent (Figure 1). Although not selectivity determining, a cation- $\pi$ interaction between the mesityl group and the sodium cation (of $\mathrm{NaO} t \mathrm{Bu}$ ) brings the base and $\mathrm{C}-\mathrm{H}$ bond in close proximity in both transition structures. Deprotonation at the more sterically hindered 2-position to form Major-Aryne-1a is favored over formation of the Minor-Aryne$1 \mathrm{a}$ by $4.08 \mathrm{kcal} / \mathrm{mol}$, which corresponds to a product ratio of $>900$ : 1 at room temperature and is consistent with the experimentally observed exclusive regioselectivity. In fact, this trend is observed for all aryl(Mes)iodonium salts (1a-o) in this study with the deprotonation at the 2-position consistently favored by $\sim 1-7 \mathrm{kcal} / \mathrm{mol}$.

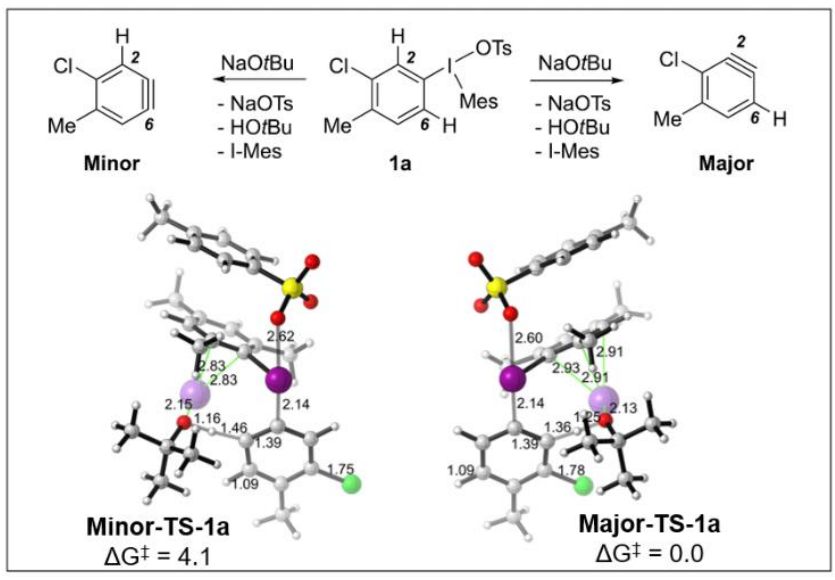

Figure 1. Computed transition structures for formation of Major and Minor-Aryne-1a. Major-TS-1a (right) is the deprotonation at the 2-position for form Major-TS-1a is favored over deprotonation at the 6-position, Minor-TS-1a (left), to form Minor-Aryne1a. Distances are in Ångströms and energies in $\mathrm{kcal} / \mathrm{mol}$.

Regiocontrol appears to stem from differential electronic stabilization of the partial negative charge formed on the aromatic ring during the deprotonation process. The developing anion is better stabilized at the 2-position rather than at the 6-position. This is primarily due to the through-bond inductive electron withdrawing effects of the iodonium moiety and the 3-position moiety rather than resonance effects which is consistent with selectivity for the proximal $\mathrm{C}-\mathrm{H}$ bond rather than the distal one. Two additional observations support this point: (1) we performed an NBO analysis of the transition structures to quantify the magnitude of orbital interaction between the $\mathrm{C}-\mathrm{H}$ bond and the substituent in the 3-position (C-Cl in Figure 1). This analysis uniformly showed that the orbital component is not significant. (2) In addition, we have performed a linear free-energy relationship analysis to correlate computed selectivities from major and minor transition structures for substrates 1a-o with common LFER parameters. We included Hammett constant for meta and para, $\sigma^{+}$, field inductive effect $(\mathrm{F})$, resonance effect $(R), A$-values, and ligand repulsive energy $\left(E_{R}\right)$. We have computed every single possible linear regression model containing these terms and their permutations of up to six-term models. The best three-term model in shown in Figure $2 .{ }^{26}$ The field inductive effect and the resonance effect ${ }^{27}$ from the 3-position substituent $\left(\mathrm{F}_{3}\right.$ and $\left.\mathrm{R}_{3}\right)$, and the $\sigma^{+}$of the 4-position substituent $\left(\sigma^{+}{ }_{4}\right)$ all contribute to the stabilization of the partial negative charge formed during deprotonation (Eq. 1). Larger field inductive effects and smaller resonance effects correlate with greater stability for deprotonation at the 2-position relative to the 6-position with the contribution from inductive effects being approximately nine times more significant than those from resonance effects. This is consistent with the moiety at the 3-position being able to stabilize deprotonation at the 2-position by inductive electron withdrawing effects while being able to stabilize deprotonation at the 2- and 6-positions though resonance effects. The significant field inductive effect associated with the iodonium moiety ${ }^{15}$ is also required to deprotonate the ortho position of the aryl group in substrates 1a-o and aligns with entries 2-6 in Table 1. There is also a small stabilizing effect correlated with larger steric bulk ${ }^{28}$ (as approximated using A-values) at the 4-position.

$$
\mathrm{Y}=5.35351-17.66168\left(\mathrm{~F}_{3}\right)+2.04654\left(\mathrm{R}_{3}\right)-3.20116\left(\sigma^{+}{ }_{4}\right) \mathbf{E q .} \mathbf{1}
$$

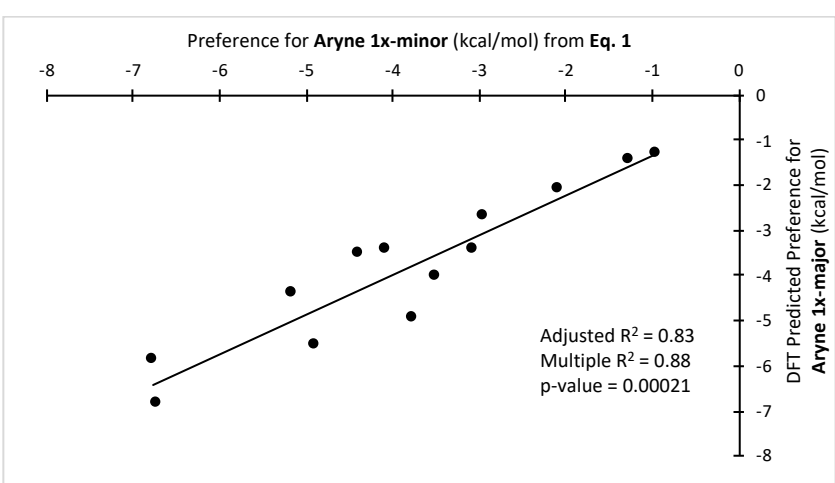

Figure 2. Linear Free Energy Relationship between the DFTpredicted preference for the formation of Major and Minor-1xAryne products as given by Eq. 1.

In conclusion, we have described a strategy to functionalize sterically hindered aryl $\mathrm{C}-\mathrm{H}$ bonds from aryl(Mes)iodonium salts and aryne intermediates. This strategy leads to synthetically challenging and important densely functionalized 1,2,3,4-substituted benzenoid building blocks. Functional group compatibility of aryl bromides allows for downstream derivatization using conventional palladium-catalysis. Arynophiles that undergo annulation or $\sigma$ bond insertion with the intermediate aryne introduce new $\mathrm{C}-\mathrm{C}, \mathrm{C}-$ $\mathrm{O}, \mathrm{C}-\mathrm{N}, \mathrm{C}-\mathrm{Cl}$, and $\mathrm{C}-\mathrm{Si}$ bonds. Additionally, dual C-H functionalization elaborates simple arenes via the intermediacy of both aryl(Mes)iodonium salts and aryne intermediates in a regiocontrolled fashion. Finally, insight obtained from DFT calculations highlights a novel cation- $\pi$ interaction that initiates $\mathrm{C}-\mathrm{H}$ deprotonation and regioselectivity that includes contributions from field inductive effects, resonance effects, and steric effects. We are continuing to elaborate upon this platform to access other challenging substitution patterns.

\section{ASSOCIATED CONTENT}

\section{Supporting Information}

Experimental procedures, X-ray and spectral data (PDF), computational data $(\mathrm{PDF})$ 


\section{AUTHOR INFORMATION}

\section{Corresponding Author}

dstuart@pdx.edu (experimental details)

paul.cheong@oregonstate.edu (computational details)

\section{ORCID}

David R. Stuart: 0000-0003-3519-9067

Paul H.-Y. Cheong: 0000-0001-6705-2962

Kevin S. Brown: 0000-0003-2959-2401

\section{Notes}

The authors declare no competing financial interests.

1 (a) Föster, H.; Vögtle, F. Steric Interactions in Organic Chemistry: Spatial Requirements of Substituents. Angew. Chem. Int. Ed. 1977, 16, 429441. (b) March, J. Advanced Organic Chemistry: Reactions, Mechanism, and Structure $4^{\text {th }}$ ed.; John Wiley \& Sons: New York, 1992; pp 501-568.

2 (a) Herrmann, R. I.; Rae, I. D. The Effects of Electronic Buttressing on the Conformations of Some ortho-Disubstituted Benzenes. Aust. J. Chem. 1972, 25, 811-815. (b) Orlek, B. S.; Sammes, P. G.; Weller, D. J. Use of Steric Buttresses to Enhance Intramolecular Cycloadditions. J. Chem. Soc. Chem. Commun. 1993, 1412-1413. (c) Decouzon, M.; Ertl, P.; Exner, O.; Gal, J.-F.; Maria, P.-C. Concepts of Sterically Hindered Resonance and Buttressing Effect: Gas-Phase Acidities of Methyl-Substituted Benzoic Acids and Basicities of Their Methyl Esters. J. Am. Chem. Soc. 1993, 115, 12071-12078. (d) Anderson, J. E.; Bru-Capdeville, V.; Kirsch, P. A.; Lomas, J. S. Attractive Steric Interactions within Molecules. The Masking of Effects in meta-Disubstituted Benzenes by Buttressed Repulsive Interactions. J. Chem. Soc. Chem. Commun. 1994, 1077-1078. (e) Heiss, C.; Cottet, F.; Schlosser, M. meta- Rather then ortho-Directed Metalations: Buttressing Effects Prejudicing the Proton Abstration from (2,6-Dihalophenyl)silanes. Eur. J. Org. Chem. 2005, 5236-5241.

${ }^{3}$ For representative examples of $\mathrm{C}-\mathrm{H}$ functionalization at the most sterically accessible position, see: (a) Fang, P.; Li, M.; Ge, H. Room Temperature Palladium-Catalyzed Decarbonylative ortho-Acylation of Acetanilides with $\alpha$-Oxocarboxylic Acids. J. Am. Chem. Soc. 2010, 132, 11898-11899. (b) Giri, R.; Lam, J. K.; Yu, J.-Q. Synthetic Applications of Pd(II)Catalyzed C-H Carboxylation and Mechanistic Insights: Expedient Routes to Anthrallic Acids, Oxazolinonones, and Quinazolinones. J. Am. Chem. Soc. 2010, 132, 686-693. (c) Bedford, R. B.; Haddow, M. F.; Mitchell, C. J.; Webster, R. L. Mild C-H Halogenation of Anilides and Isolation of an Unusual Palladium(I)-Palladium(II) Species. Angew. Chem. Int. Ed., 2011, 50, 5524-5527. (d) Preshlock, S. M.; Ghaffari, B.; Maligres, P. E.; Krska, S. W.; Maleczka, R. E. Jr.; Smith, M. R. III. High-Throughput Optimization of Ir-Catalyzed C-H Borylation: A Tutorial for Practical Applications. J. Am. Chem. Soc. 2013, 135, 7572-7582. (e) Rodriguez, R. A.; Pan, C.-M.; Yabe, Y.; Kawamata, Y.; Eastgate, M. D.; Baran, P. S. Palau'chlor: A Practical and Reactive Chlorinating Reagent. J. Am. Chem. Soc. 2014, 136 6908-6911. (f) Fernández-Salas, J. A.; Eberhart, A. J.; Procter, D. J. MetalFree $\mathrm{CH}-\mathrm{CH}$ Type Cross-Coupling of Arenes and Alkynes Directed by a Multifunctional Sulfoxide Group. J. Am. Chem. Soc. 2016, 138, 790-793. (g) Yanagi, T.; Otsuka, S.; Kasuga, Y.; Fujimoto, K.; Murakami, K.; Nogi, K.; Yorimitsu, H.; Osuka, A. Metal-Free Approach to Biaryls from Phenols and Aryl Sulfoxides by Temporarily Sulfur-Tethered Regioselective CH/C-H Coupling. J. Am. Chem. Soc. 2016, 138, 14582-14585. (h) Davis, H. J.; Mihai, M. T.; Phipps, R. J. Ion Pair-Directed Regiocontrol in Transition-Metal Catalysis: A Meta-Selective C-H Borylation of Aromatic Quaternary Ammonium Salts. J. Am. Chem. Soc. 2016, 138, 12759-12762. (i) Wang, X-Y.; Dienel, T.; Di Giovannantionio, M.; Barin, G. B.; Karche, N.; Deniz, O.; Urgel, J. I.; Widmer, R.; Stolz, S.; De Lima, L. H.; Muntwiler, M.; Tommasisi, M.; Meuneir, V.; Ruffieux, P.; Feng, X.; Fasel, R.; Müller, K.; Narita, A. Heteroatom-Doped Perihexacene from a Double Helicene Precursor: On-Surface Synthesis and Properties. J. Am. Chem. Soc. 2017 139, 4671-4674. (j) Wang, J.; Li, R.; Dong, Z.; Liu, P.; Dong, G. Complementary Site-Selectivity in Arene Functionalization Enabled by Overcoming the Ortho Constraint in Palladium/Norbornene Catalysis. Nat. Chem. 2018, 10, 866-872.

\section{ACKNOWLEDGMENT}

We acknowledge Portland State University for partial financial support of this work. The National Science Foundation provided instrumentation funding for the BioAnalytical Mass Spectrometry Facility at PSU (NSF, MRI 1828573) and X-ray diffraction center at the University of Portland (NSF, MRI 0604188). PHYC is the Bert and Emelyn Christensen professor of OSU, and gratefully acknowledges financial support from the Vicki \& Patrick F. Stone family, the National Science Foundation (NSF, CHE-1352663).

\section{REFERENCES}

${ }^{4}$ Robinson, J. M.; Sakai, T.; Okano, K.; Kitawaki, T.; Danheiser, R. L. Formal $[2+2+2]$ Cycloaddition Strategy Based on an Intramolecular Propargylic Ene Reaction/Diels-Alder Cycloaddition Cascade. J. Am. Chem. Soc. 2010, 132, 11039-11041

${ }^{5}$ Mack, K. A.; Collum, D. B. Case for Lithium TetramethylpiperidideMediated Ortholithiations: Reactivity and Mechanisms. J. Am. Chem. Soc. 2018, $140,4877-4883$.

${ }^{6}$ For leading references, see: (a) Medina, J. M.; Mackey, J. L.; Garg, N. K.; Houk, K. N. The Role of Aryne Distortions, Steric Effects, and Charges in Regioselectivity of Aryne Reactions. J. Am. Chem. Soc. 2014, 136, 15798-15805. (b) Picazo, E.; Houk, K. N.; Garg, N. K. Computational predictions of substituted benzyne and indolyne regioselectivity. Tetrahedron Lett. 2015, 56, 3511-3514.

${ }^{7}$ For recent reviews, see: (a) Tadross, P. M.; Stoltz, B. M. A Comprehensive History of Arynes in Natural Product Total Synthesis. Chem. Rev. 2012, 112, 3550-3577. (b) Gampe, C. M.; Carreira, E. M. Arynes and Cyclohexynes in Natural Product Synthesis. Angew. Chem. Int. Ed. 2012, 51, 3766-3776. (c) Bhunia, A.; Reddy, S.; Biju, A. T. Recent advances in transition-metal-free carbon-carbon and carbon-heteroatom bond-forming reactions using arynes. Chem. Soc. Rev. 2012, 41, 3140-3152. (d) Dubrovskiy, A. V.; Markina, N. A.; Larock, R. C. Use of benzyne for the synthesis of heterocycles. Org. Biomol. Chem. 2013, 11, 191-218. (e) Yoshida, S.; Hosoya, T. The Renaissance and Bright Future of Synthetic Aryne Chemistry. Chem. Lett. 2015, 44, 1450-1460. (f) Yoshimura, A.; Saito, A.; Zhdankin, V. V. Iodonium Salts as Benzyne Precursors. Chem. Eur. J. 2018, 24, $15156-15166$

${ }^{8}$ Bifunctional aryne precursors, such as Kobayashi and related reagents are less effective toward this end because of the synthetic inefficiency and challenges of installing the requisite activating (TMS) and leaving (OTf) groups.

${ }^{9}$ Recent examples, see: (a) Yuan, Y.; Thomé, I.; Kim, S. H.; Chen, D.; Beyer, A.; Bonnamour, J.; Zuidema, E.; Chang, S.; Bolm, C. Dimethyl Sulfoxide/Potassium Hydroxide: A Superbase for the Transition Metal-Free Preparation of Cross-Coupling Products. Adv. Synth. Catal. 2010, 352, 2892-2898. (b) Truong, T.; Daugulis, O. Base-Mediated Intermolecular sp C-H Bond Arylation via Benzyne Intermediates. J. Am. Chem. Soc. 2011, 133, 4243-4245. (c) Yang, S.; Wu, C.; Ruan, M.; Yang, Y.; Zhao, Y.; Niu, J.; Yang, W.; Xu, J. Metal- and ligand-free Ullman-type C-O and C-N coupling reactions promoted by potassium tert-butoxide. Tetrahedron Lett. 2012, 53, 4288-4292. (d) Truong, T.; Daugulis, O. Divergent reaction pathways for phenol arylation by arynes: synthesis of helicenes and 2-arylphenols. Chem. Sci., 2013, 4, 531-535. (e) Truong, T.; Mesgar, M.; Khac, K.; Le, A.; Daugulis, O. General Method for Functionalized Polyaryl Synthesis via Aryne Intermediates. J. Am. Chem. Soc. 2014, 136, 8568-8576. (f) Dong, Y.; Lipschutz, M. I.; Tilley, T. D. Regioselective, Transition MetalFree C-O Coupling Reactions Involving Aryne Intermediates. Org. Lett. 2016, 18, 1530-1533. (g) Mesgar, M.; Nguyen-Le, J.; Daugulis, O. New Hindered Amide Base for Aryne Insertion in Si-P, Si-S, Si-N, and C-C Bonds. J. Am. Chem. Soc., 2018, 140, 13703-13710. (h) Cho, S.; Wang, Q. ortho-Difunctionalization of arynes by $\mathrm{LiZnEt}_{2}$ (TMP)-mediated deprotonative zincation/elimination of aryl triflates. Tetrahedron 2018, 74, 33253328.

${ }^{10}$ Cant, A. A.; Roberts, L.; Greaney, M. F. Generation of benzyne from benzoic acid using C-H activation. Chem. Commun. 2010, 46, 8671-8673. 
11 Devaraj, K.; Ingner, F. J. L.; Sollert, C.; Gates, P. J.; Orthaber, A.; Pilarski, L. T. Arynes and Their Precursors from Arylboronic Acids via Catalytic C-H Silylation. J. Org. Chem. 2019, 84, 5863-5871.

12 Dyke, A. M.; Gill, D. M.; Harvey, J. N.; Hester, A. J.; Lloyd-Jones, G. C.; Munoz, M. P.; Shepperson, I. R. Decoupling Deprotonation from Metallation: Thia-Fries Rearrangement. Angew. Chem. Int. Ed. 2008, 47 5067-5070.

13 Bunnett, J. F.; Kearley, F. J. Jr. Comparative Mobility of Halogens in Reactions of Dihalobenzenes with Potassium Amide in Ammonia. J. Org. Chem. 1971, 36, 184-186.

14 (a) Wickham, P. P.; Hazen, K. H.; Guo, H.; Jones, G.; Reuter, K. H.; Scott, W. J. Benzyne Generation from Aryl Triflates. J. Org. Chem. 1991, 56, 2045-2050. (b) Tripathy, S.; LeBlanc, R.; Durst, T. Formation of 2Substituted Iodobenzenes from Iodobenzene via Benzyne and Ate Complex Intermediates. Org. Lett. 1999, 1, 1973-1975.

${ }^{15}$ For $\sigma_{\mathrm{m}}$ of phenyliodonium, see: (a) Mironova, A. A.; Maletina, I. I.; Iksanova, S. V.; Orda, V. V.; Yagupolskii, L. M. Electronic Nature of Substituents Containing Polyvalent Iodine. Zh. Org. Chem. 1989, 25, 306-311. For relative leaving group ability of phenyliodonium, see: (b) Okuyama, T.; Takino, T.; Sueda, T.; Ochiai, M. Solvolysis of Cyclohexenyliodonium Salt, a New Precursor for the Vinyl Cation: Remarkable Nucleofugality of the Phenyliodonio Group and Evidence for Internal Return from an Intimate Ion-Molecule Pair. J. Am. Chem. Soc. 1995, 117, 3360-3367.

16 The 1,2,4-substitution pattern in $\mathbf{1 a}$ is readily accessible by $\mathrm{S}_{\mathrm{E}} \mathrm{Ar}$ and widely commercially available.

17 (a) Yoshida, H.; Shirakawa, E.; Honda, Y.; Hiyama, T. Addition of Ureas to Arynes: Straightforward Synthesis of Benzodiazepine and Benzodiazocine Derivatives. Angew. Chem. Int. Ed. 2002, 41, 3247-3249. (b) Shah, T. K.; Medina, J. M.; Garg, N. K. Expanding the Strained Alkyne Toolbox: Generation and Utility of Oxygen-Containing Strained Alkynes. J. Am. Chem. Soc. 2016, 138, 4948-4954.

18 (a) Sundalam, S. K.; Nilova, A.; Seidl, T. L.; Stuart, D. R. A Selective C-H Deprotonation Strategy to Access Functionalized Arynes by Using Hypervalent Iodine. Angew. Chem. Int. Ed. 2016, 55, 8431-8434. (b) Stuart, D. R. Unsymmetrical Diaryliodonium Salts as Aryne Synthons: Renaissance of a C-H Deprotonative Approach to Arynes. Synlett 2017, 28, 275 279.

19 The mass balance appears to be a dual insertion product of aryne into each of the C-N bonds of the urea, which is minimized at the standard conditions with 3 equivalents of urea. Previous methods typically employ $>10$ equivalents of urea as the solvent.
${ }^{20}$ Although minor signals in the aromatic region of crude ${ }^{1} \mathrm{H}$ NMR spectrum were difficult to assign, GCMS analysis of crude reaction mixtures did not reveal other regioisomeric products.

${ }^{21}$ Wagen, C. C.; Ingoglia, B. T.; Buchwald, S. L. Unexpected Formation of Hexasubstituted Arenes through a 2-fold Palladium-Mediated Ligand Arylation. J. Org. Chem. 2019, DOI: 10.1021/acs.joc.9b02091.

22 Suzuki, see: (a) Walker, S. D.; Barder, T. E.; Martinelli, J. R.; Buchwald, S. L. A Rationally Designed Universal Catalyst for Suzuki-Miyaura Coupling Processes. Angewandte Chemie Int. Ed. 2004, 43, 1871-1876. Buchwald-Hartwig, see: Surry, D. S.; Buchwald, S. L.; Dialkylbiaryl Phosphines in Pd-Catalyzed Amination: A User's Guide. Chem. Sci. 2011, 2, $27-50$.

23 (a) Y. Zhao and D. G. Truhlar, Theor. Chem. Acc., 2008, 120, 215 241; (b) P. C. Hariharan and J. A. Pople, Theor. Chim. Acta, 1973, 28, 213 222; (c) W. J. Hehre, R. Ditch $\square$ eld and J. A. Pople, J. Chem. Phys., 1972, 56, 2257-2261; (d) S. Miertu`s, E. Scrocco and J. Tomasi, Chem. Phys., 1981, 55, 117-129.

24 (a) Check, C. E.; Faust, T. O.; Bailey, J. M.; Wright, B. J.; Gilbert, T. M.; Sunderlin, L. S. J. Phys. Chem. A, 2001, 105, 8111-8116. (b) Wadt, W. R.; Hay, P. J. J. Chem. Phys., 1985, 82, 284-298.

${ }^{25}$ Transition structures involving compound 1c could not be isolated in our hands and have been excluded from the discussion.

${ }^{26}$ Overfitting is a serious problem in cases with many predictors and few measurements. In order to guard against this, we performed the following two things: (1) The selectivity values were scrambled and new linear free energy relationships were computed; the models produced were poor. Even the best five term model only exhibited an $R^{2}$ of 0.3922 . (2) The selectivity values were scrambled, and the best three-term model found for the real data (Eq. 1) was used to predict the scrambled data; this gave starkly different results from what we observed when we matched to the real selectivity data. See Supporting Information.

${ }^{27}$ Hansch, C.; Leo, A.; Taft, R. W. A Survey of Hammett Substituent Constants and Resonance and Field Parameters. Chem. Rev. 1991, 91, 165195.

${ }^{28}$ Anslyn, E. V.; Dougherty, D. A. Modern Physical Organic Chemistry 2006, University Science Books: Sausalito, CA, p. 104.

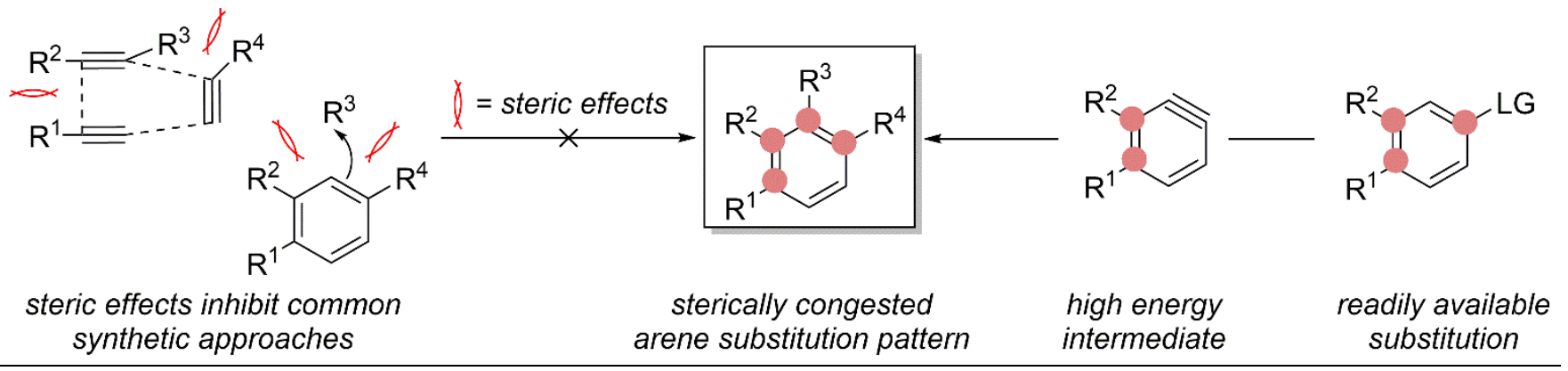

